\title{
Modelling the effect of nematode parasites on the liveweight gain of lambs grazing alternately with cattle
}

\author{
K. LOUIE ${ }^{1}$, C.J. BOOM ${ }^{1}$, R.A. DYNES ${ }^{2}$ and A.D. MACKAY ${ }^{3}$ \\ AgResearch, ${ }^{1}$ Ruakura Research Centre, Private Bag 3123, Hamilton \\ ${ }^{2}$ Lincoln Centre, Gerald Street, Private Bag 4749, Christchurch \\ ${ }^{3}$ Grasslands Research Centre, Private Bag 11008, Palmerston North \\ robyn.dynes@agresearch.co.nz
}

\begin{abstract}
A dynamic model for nematode parasites in lambs which links their adult parasite burden with liveweight gain was extended to investigate alternate grazing with cattle to provide relatively larval-free pasture for finishing lambs. Liveweight performance of weaned lambs was tracked fortnightly under rotational grazing using three cattle:sheep ratios, with three initial parasite burdens and two initial infective larval densities on pasture. Lambs were removed from grazing at $37 \mathrm{~kg}$ or if they failed to gain weight during the preceding fortnight. An 80\%:20\% cattle:sheep ratio reduced larval pasture contamination by $75 \%$ but did not affect parasitic burden and total lamb liveweight gain compared with an all-lamb treatment. For low and moderate initial parasitic burdens in the $80 \%: 20 \%$ cattle:sheep ratio, $25 \%$ of lambs reached $37 \mathrm{~kg}$ and $100 \%$ gained weight until week 18 . This simulation indicated that in organic lamb finishing systems, alternate grazing with cattle provides substantial benefit but only when the initial parasite burden was low or moderate.
\end{abstract}

Keywords: modelling, parasites, liveweight gain, alternate grazing

\section{Introduction}

Nematode parasite infections in grazing lambs remain one of the major constraints to high performance (Rattray 2003). Increasing concern about the reliance on chemical drenches for parasite control has led to renewed interest in alternative strategies for minimising effects of parasitism. One strategy is to use alternate grazing with cattle (Barger \& Southcott 1978; Moss et al. 1998) to reduce contamination of sheep-specific third-stage infective larvae (L3) on pastures. The rationale behind this strategy is that the majority of nematode parasites are host-specific e.g. Ostertagia ostertagi in cattle, Haemonchus contortus, Teladorsagia circumcincta and Trichostrongylus colubriformis in sheep (Pomroy 1997), and thus cattle will remove sheep L3 larvae whilst grazing and vice versa. The susceptible stock will then return to graze on pasture with reduced L3 larvae levels, possibly reducing parasitic burden and therefore improving total liveweight gain (LWG) and reducing the need for anthelmintic drenching.

Previous simulations (Louie et al. 2006) indicated that for a significant increase in total LWG due to relatively L3 larval-free pasture, a rotation length of at least 6 weeks was required. Also, we considered L3 larvae specific only to sheep, with the cattle acting as L3 larvae removers whilst keeping pasture cover and quality within reasonable limits. The duration for the development of eggs to the L3 larvae stage is shorter at higher temperatures (Leathwick et al. 1992) and duration from ingested L3 larvae to adult worms also varies (Leathwick et al. 1992). In the model we assumed that these durations were 14 days and 21 days respectively. The effect of varying cattle:sheep ratio on lamb LWG was investigated for a range of initial parasite burdens on an initially L3-free or contaminated pasture. This required a dynamic modelling approach because the parasite development durations will interact with the rotation length to give complex behaviour of the parasite population.

\section{Method}

\section{Model description}

The dynamic, individually based host-parasite model used to simulate liveweights and parasite burdens for grazing lambs has been detailed in Louie et al. (2007). Simply, the model assumed the effects of adult parasites was to reduce feed intake and amount of energy allocated to LWG whilst increasing the energy required for maintenance. The modifications required to simulate alternate grazing involved the introduction of descriptive variables for the cattle. These are analogous to the existing variables for the lambs (Louie et al. 2007), although, in the case of fully resistant cattle, it is only liveweight which changes since their immunity level and parasite burden would remain constant. Lambs were drafted fortnightly when they reached $37 \mathrm{~kg}$ liveweight. Furthermore, those lambs which failed to gain weight in the preceding fortnight in organic systems would be drenched and also removed from the flock having lost their organic status. If many were drafted or drenched and removed, the remaining lambs would face decreased grazing pressure. However, under the stocking rates and 
rotation length considered here, the effect on their pasture intake was small.

\section{Model scenarios}

Three stock unit based cattle:sheep ratios, three levels of parasitic burden at weaning and two initial levels of L3 larval density were examined in a factorial design. For simplicity, in this modelling exercise we used fully parasite-resistant cattle grazing with finishing lambs in a rotational system of six paddocks with rotation length of 6 weeks over a 24 week period. Rotation lengths shorter than 6 weeks do not allow sufficient time for L3 larvae levels on the paddocks to decline before the lambs regraze. The cattle:sheep ratios were:

(1) $0 \%: 100 \%$, (0 cattle, 90 lambs)

(2) $50 \%: 50 \%$, , (5 cattle, 45 lambs)

(3) $80 \%: 20 \%$ ( 8 cattle, 18 lambs)

and calculated so each treatment initially had the same daily feed demand at the beginning of the 24 week grazing period. The three initial parasite burden levels chosen were 2000, 5000 and 10000 adult parasites per lamb, representing typical low to high values at weaning on an organic unit (Devantier et al. 2005) and assumed to be dominated by Trichostrongylus species. The initial L3 larval density was either zero or $1000 \mathrm{~L} 3 / \mathrm{kg} \mathrm{DM}$, and this latter value is not atypical for pasture in December (Vlassoff et al. 2001). The initial unfasted weight of lambs and cattle was 25 and $300 \mathrm{~kg}$ respectively, and they were assumed to eat $4 \%$ and $3 \%$ of their current liveweight, respectively, in pasture DM per day. Grazing took place on a three hectare block divided into six paddocks, each initially containing 2000 $\mathrm{kg} \mathrm{DM} / \mathrm{ha}$ pasture mass, and pasture growth was assumed to vary seasonally. Lambs commenced grazing on paddock 4 and cattle on paddock 1, remaining in each paddock for 1 week and thus allowing a 2 week period between lambs and cattle grazing in any single paddock as shown in the following diagram.

\begin{tabular}{c|c|c}
\hline Paddock 1 & Paddock 2 & Paddock 3 \\
\hline $\begin{array}{c}\text { Cattle } \\
\text { commenced } \\
\text { grazing here }\end{array}$ & & \\
\hline
\end{tabular}

\begin{tabular}{c|c|c}
\hline Paddock 4 & Paddock 5 & Paddock 6 \\
\hline $\begin{array}{c}\text { Lambs } \\
\text { commenced } \\
\text { grazing here }\end{array}$ & & \\
\hline
\end{tabular}

Cattle and lambs were moved to the following paddock every week so cattle followed the rotation scheme 1,2, 3, 4, 5 and 6 whilst lambs were on 4, 5, 6, 1,2 and 3, both repeated four times.

\section{Results}

The impact of initial lamb parasite burden and pasture contamination on number of lambs reaching the target weight of $37 \mathrm{~kg}$ is shown in Table 1 . The time at which the lambs were drafted is shown in Figure 1. When on initially clean pasture, increasing the initial parasite burden from 2000 to 10000 reduced the proportion of lambs finished from $100 \%$ to $30 \%$. The presence of cattle had little effect on these proportions, although, with an initial parasite burden of 5000, higher cattle:sheep ratios did enable lambs to grow faster from weeks 12 to 18 of grazing (Fig. 1C).

Commencing grazing on L3 larvae contaminated pasture reduced the proportion of lambs finished. Grazing at $80 \%: 20 \%$ cattle:sheep ratio resulted in the lowest proportion finished when initial parasite burden was 10 000 (Fig. 1F).

The impact of initial parasite burden and pasture contamination on number of lambs requiring drenching is shown in Table 2. The time at which the lambs were drenched is shown in Figure 2. Drenching rates were higher on contaminated pasture irrespective of initial parasite burden. Increasing cattle:sheep ratio also increased the final drenched proportion at 24 weeks on contaminated pasture. Drenching was delayed with increasing cattle:sheep ratio irrespective of initial pasture contamination.

The impact of initial parasite burden and pasture contamination on number of lambs continuing to gain weight but failing to reach $37 \mathrm{~kg}$ (store lambs) is shown in Table 3.

Unfinished lamb numbers increased with initial parasite burden but declined with increasing cattle:sheep ratio. However, if lambs had high initial parasite burdens neither cattle:sheep ratio nor initial presence of L3 larvae on pasture affected the proportion of unfinished lambs. The cattle:sheep ratio had little impact on the average total LWG of the store lambs as shown in Figure 3.

The main effect of increasing cattle:sheep ratio was on the L3 larval density in the pasture. This is shown in Figure 4 for the paddock on which the lambs commenced grazing. There was a large reduction in peak L3 larval density at week 15 compared to the all-lamb treatment as the cattle:sheep ratio was increased. The L3 larval density takes two rotation lengths (12 weeks) to build up to its peak value. The largest peak L3 larval density occurred for the initial parasite burden of 5000 rather than 10000 when only lambs are grazing. This is because a greater number of lambs were drenched and removed for the 
Table 1 Number of lambs reaching $37 \mathrm{~kg}$ liveweight after 24 weeks grazing with no cattle (90 lambs), $50 \%$ cattle (45 lambs) or $80 \%$ cattle (18 lambs) with larval parasite contamination on pasture of 0 or $1000 \mathrm{L3} / \mathrm{kg} \mathrm{dry}$ matter.

\begin{tabular}{lcccccc}
\hline $\begin{array}{l}\text { Initial parasitic } \\
\text { burden }\end{array}$ & \multicolumn{2}{c}{$0 \%$ Cattle: sheep ratio } & \multicolumn{2}{c}{$80 \%: 20 \%$} \\
No. adults & 0 & 1000 & 0 & 1000 & 0 & 1000 \\
\hline 2000 & 90 & 70 & 45 & 34 & 18 & 13 \\
5000 & 59 & 48 & 32 & 23 & 14 & 9 \\
10000 & 27 & 21 & 11 & 7 & 5 & 2 \\
\hline
\end{tabular}

Figure 1 The proportion of the flock reaching target weight and time taken to achieve this. $\bigcirc=$ lambs only, $\diamond$ $=50 \%: 50 \%$ and $\square=80 \%: 20 \%$ cattle:sheep ratio respectively. Rows correspond to initial parasitic burdens of 2000 (1A, B), 5000 (1C, D) and 10000 (1E, F) respectively.

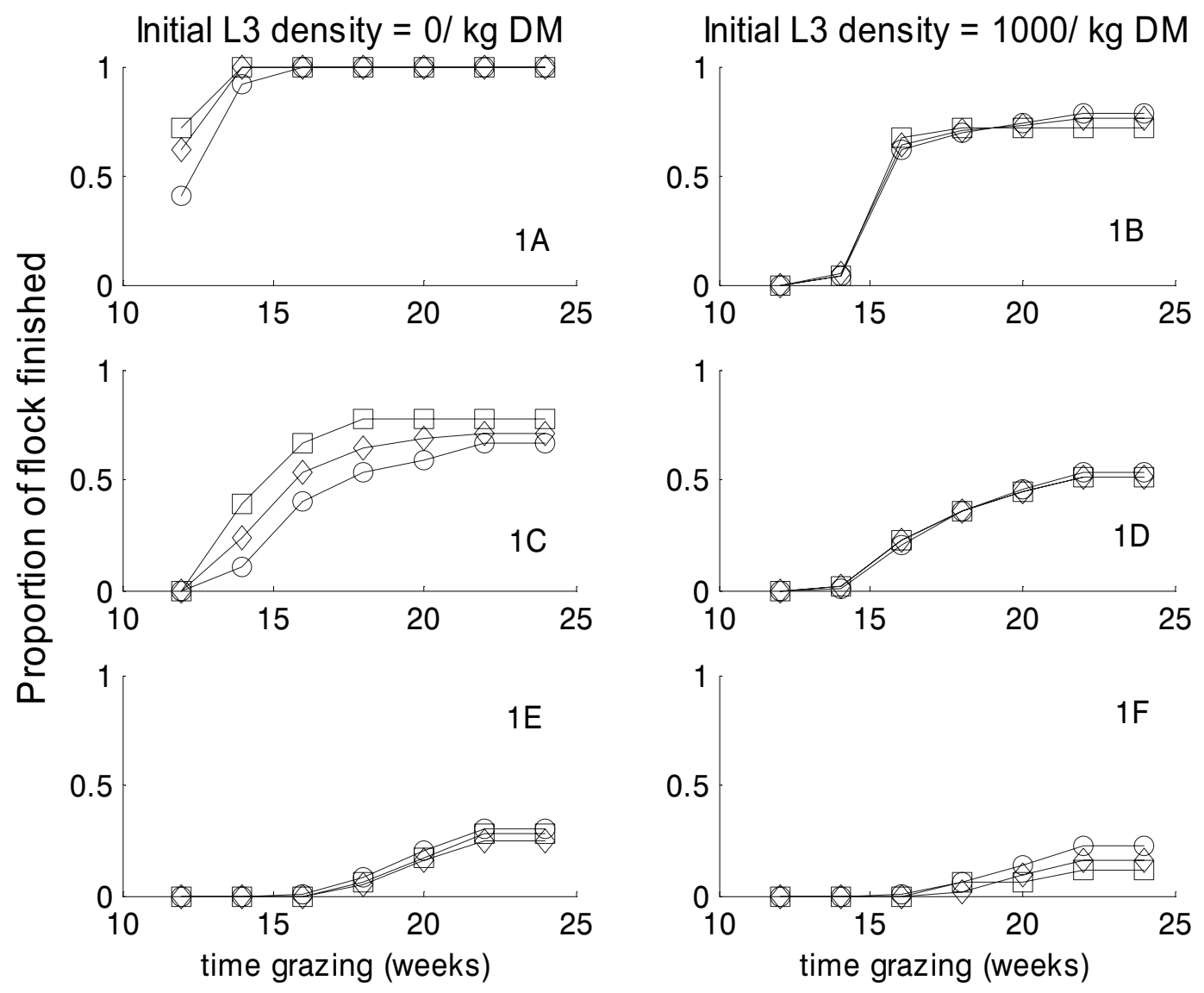

Table 2 Number of lambs drenched and removed after 24 weeks grazing with no cattle (90 lambs), 50\% cattle (45 lambs) or $80 \%$ cattle (18 lambs) with larval parasite contamination on pasture of 0 or $1000 \mathrm{~L} 3 / \mathrm{kg}$ dry matter.

\begin{tabular}{lcccccc}
\hline $\begin{array}{l}\text { Initial parasitic } \\
\text { burden }\end{array}$ & \multicolumn{2}{c}{$0 \%$ Cattle: sheep ratio } & \multicolumn{2}{c}{$80 \%: 20 \%$} \\
No. adults & 0 & 1000 & 0 & 1000 & 0 & 1000 \\
\hline 2000 & 0 & 12 & 0 & 9 & 0 & 5 \\
5000 & 18 & 23 & 10 & 13 & 4 & 7 \\
10000 & 35 & 40 & 17 & 21 & 8 & 10 \\
\hline
\end{tabular}


Figure 2 The proportion of the flock requiring drenching and the time at which this is done. $\bigcirc=$ lambs only, $\diamond$ $=50 \%: 50 \%$ and $\square=80 \%: 20 \%$ cattle:sheep ratio (on a stock unit basis) respectively. Rows correspond to initial parasitic burdens of 2000 (2A, B), 5000 (2C, D) and 10000 adult parasites/head $(2 \mathrm{E}, \mathrm{F})$ respectively.

Initial L3 density $=0 / \mathrm{kg} D M$

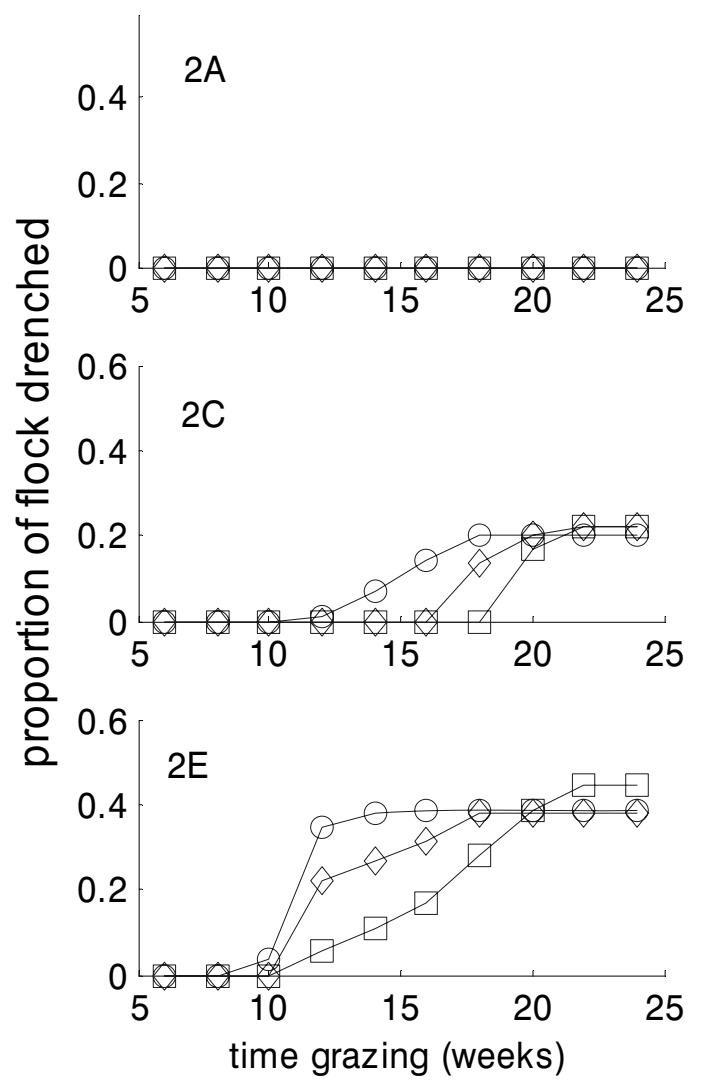

Initial L3 density $=1000 / \mathrm{kg}$ DM
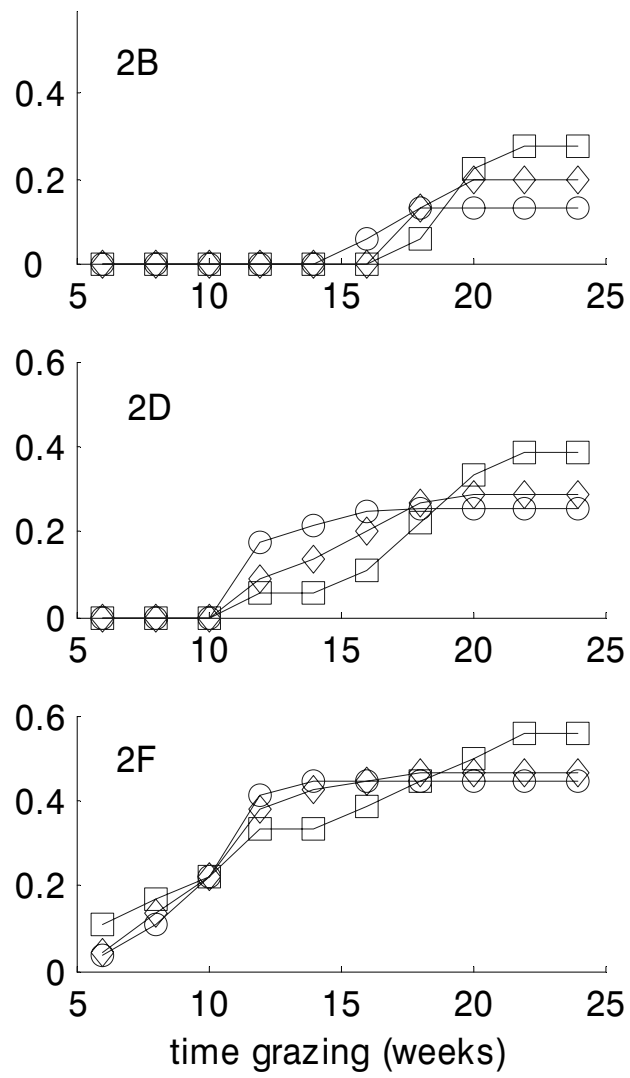

Table 3 Number of lambs failing to reach $37 \mathrm{~kg}$ but continuing to gain weight after 24 weeks' grazing with no cattle (90 lambs), $50 \%$ cattle (45 lambs) or $80 \%$ cattle (18 lambs) with larval parasite contamination on pasture of 0 or 1000 L3/kg dry matter.

\begin{tabular}{|c|c|c|c|c|c|c|}
\hline \multirow{2}{*}{$\begin{array}{l}\text { Initial parasitic } \\
\text { burden } \\
\text { No. adults }\end{array}$} & \multicolumn{6}{|c|}{ Cattle: sheep ratio } \\
\hline & 0 & 1000 & 0 & 1000 & 0 & 1000 \\
\hline 2000 & 0 & 8 & 0 & 2 & 0 & 0 \\
\hline 5000 & 13 & 19 & 3 & 9 & 0 & 2 \\
\hline 10000 & 28 & 29 & 17 & 17 & 5 & 6 \\
\hline
\end{tabular}

higher initial parasite burden (compare Figs. 2C \& 2E). When cattle were present, the L3 larval density at the end of the grazing period was reduced and this was more pronounced with the higher cattle:sheep ratio. This may be beneficial in the next season.

\section{Discussion}

Using cattle to remove sheep-specific L3 larvae is an appealing alternative to regular drenching, particularly for organic farmers. However, dynamic modelling shows that the results obtained will depend critically on the initial parasite burden of the lambs and whether the pasture is initially free of L3 larvae.

For initially L3 larvae-free pasture and lambs carrying a high initial parasite burden, the presence of cattle had no effect on the proportion of lambs reaching $37 \mathrm{~kg}$ after 24 weeks of grazing. When the initial parasite burden was lower, increasing the cattle:sheep ratio enabled the finishing percentage to be reached earlier than 24 weeks. When the pasture was initially contaminated, the presence 
Figure 3 The average total liveweight gain of lambs that were neither drenched nor reached $37 \mathrm{~kg}$ after 24 weeks of grazing.
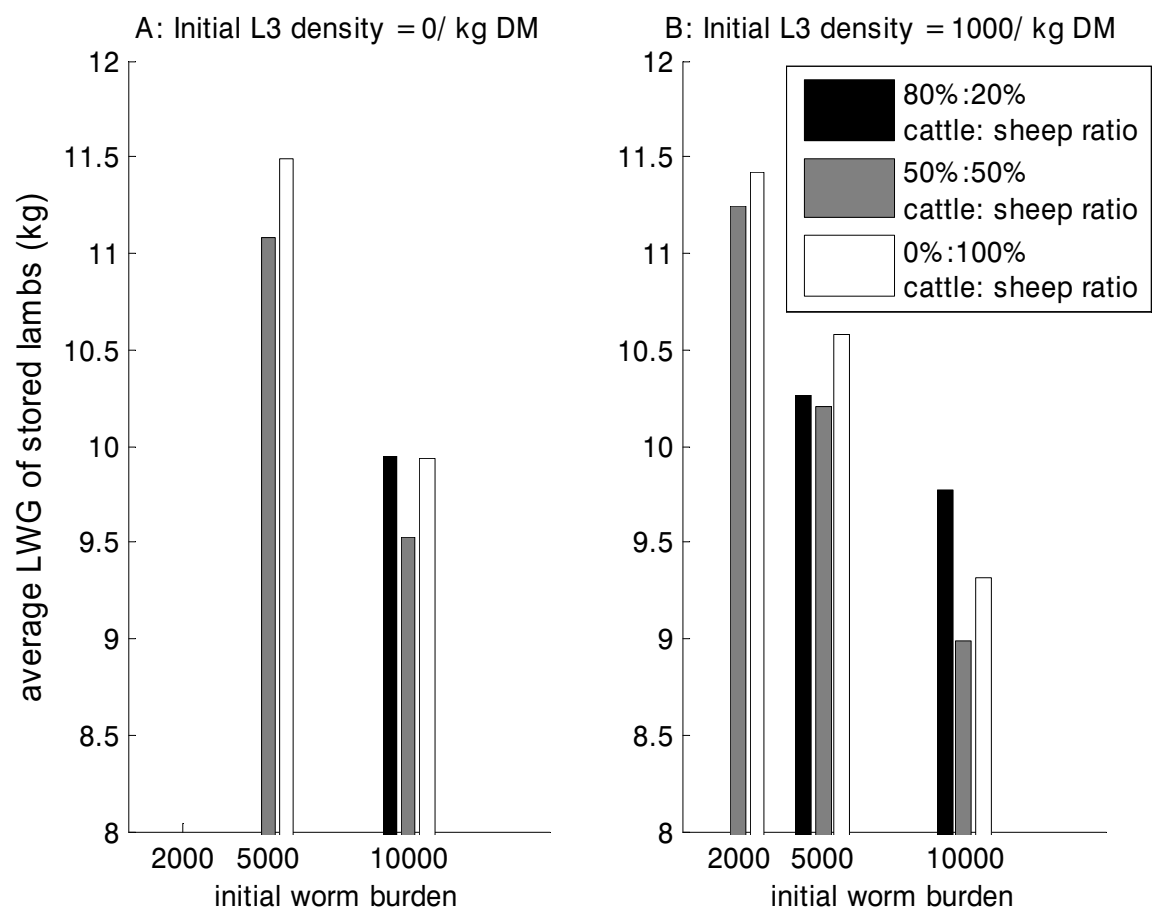

Figure 4 The effect of increasing cattle:sheep ratio on L3 larval density in paddock 3 (of 6). Dotted, solid and dashed curves are for cattle:sheep ratios of $0 \%: 100 \%, 50 \%: 50 \%$ and $80 \%: 20 \%$ (on a stock unit basis) respectively. Rows correspond to initial adult parasite burdens of 2000 (4A, B), 5000 (4C, D) and $10000(4 \mathrm{E}, \mathrm{F})$ per sheep respectively.
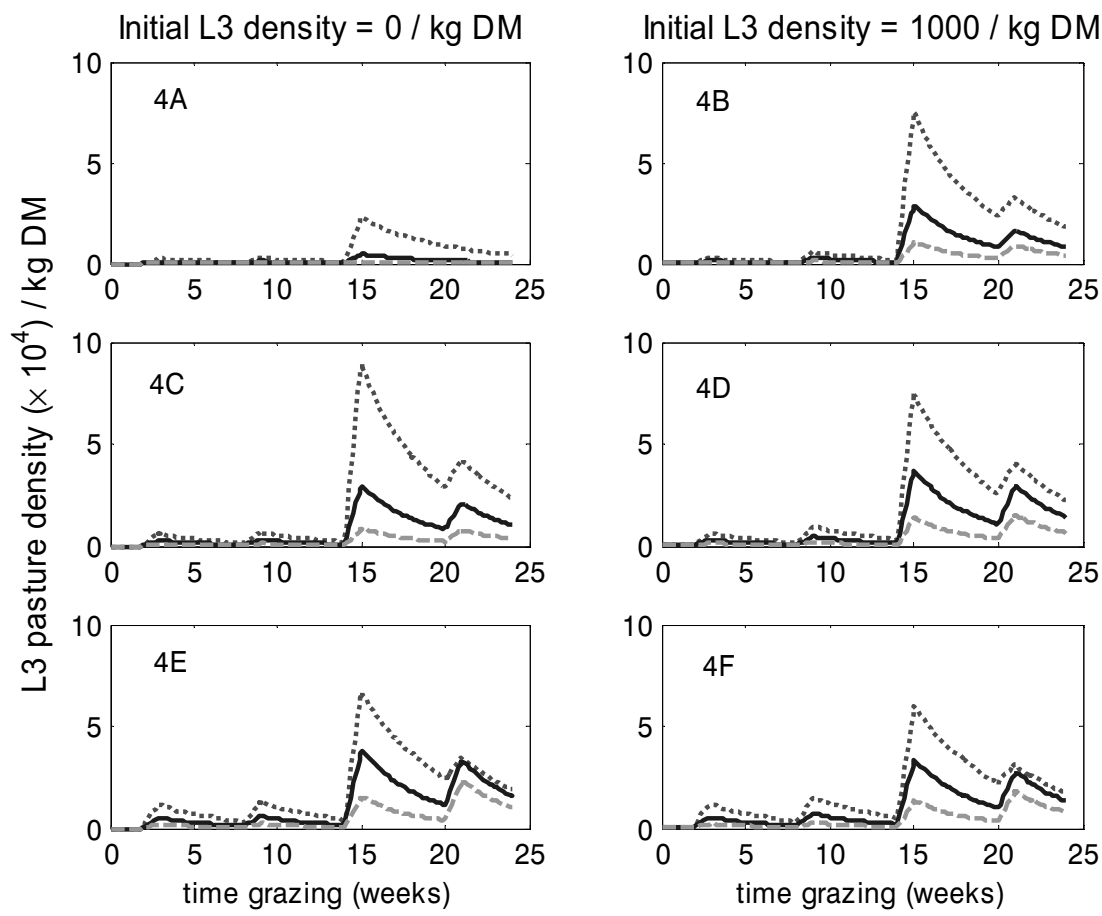
of cattle did not enable earlier finishing. Similarly, when grazing commenced on L3 larvae-free pasture, the presence of cattle did not affect the total proportion of lambs requiring drenching by 24 weeks. The cattle:sheep ratio did affect when drenching occurred, with increasing cattle:sheep ratio allowing this to be delayed by 8 to 10 weeks for both moderate and high initial parasite burden. Delayed drenching also occurred but to a smaller degree when grazing commenced on L3 larval-contaminated pasture.

The greatest impact of the cattle was on L3 larval density of the pasture. Although the high cattle:sheep ratio treatment led to the lowest L3 larval density on pasture, the mean parasite burden in that group was still higher than the all-lamb flock at the end of 24 weeks grazing. This was because many of the parasite-susceptible lambs in the all-lamb flock had been drenched and removed.

Use of cattle to remove sheep-specific L3 larvae and improve lamb performance requires good knowledge of initial parasite burden and pasture L3 larval levels. More cattle may be required than is common on most sheep/ beef farms and may not be the best use of available pasture. Natural and organic farmers are likely to need a suite of tools to minimise parasite burdens or L3 larval ingestion.

\section{ACKNOWLEDGEMENTS}

The authors would like to thank Annette Litherland and Ian Sutherland for useful comments on an earlier version of this paper. This work was funded under FRST contract C10X0236 "Natural and Organic".

\section{REFERENCES}

Barger, I.A.; Southcott, W.H. 1978. Parasitism and production in weaner sheep grazing alternately with cattle. Australian Journal of Experimental Agriculture and Animal Husbandry 18: 340-346.

Devantier, B.P.; Pomroy, W.E.; Mackay, A.D. 2005. Gastrointestinal nematode challenge in natural and organic sheep systems. In: Proceedings of the 20th International Conference of the World Association for the Advancement of Veterinary Parasitology, 16-20 October 2005, Christchurch, New Zealand.

Leathwick, D.M.; Barlow, N.D.; Vlassoff, A. 1992. A model for nematodiasis in New Zealand lambs. International Journal for Parasitology 22: 789-799.

Louie, K.; Boom, C.J.; Vlassoff, A.; Burggraaf, V.T. 2006. Modelling liveweight performance in parasitised lambs under varying grazing rotation lengths. Proceedings of the New Zealand Grassland Association 68: 149-154.

Louie, K.; Vlassoff, A.; Mackay, A.D. 2007. Gastrointestinal nematode parasites of sheep: a dynamic model for their effect on liveweight gain. International Journal for Parasitology 37: 233-241.

Moss, R.A.; Burton, R.N.; Scales, G.H.; Saville, D.J. 1998. Effect of cattle grazing strategies and pasture species on internal parasites of sheep. New Zealand Journal of Agricultural Research 41: 533-544.

Pomroy, W.E. 1997. Internal helminth parasites of ruminants in New Zealand. In: Sustainable control of internal parasites in ruminants. Animal Industries Workshop, Ed: Barrell G.K. Lincoln University, Canterbury, New Zealand.

Rattray, P.V. 2003. Helminth parasites in the New Zealand Meat \& Wool Pastoral Industries: A review of current issues. Report for Meat \& Wool Innovation Ltd.

Vlassoff, A.; Leathwick, D.M.; Heath, A.G.C. 2001. The epidemiology of nematode infections of sheep. New Zealand Veterinary Journal 49: 213-221. 